\title{
Primary and secondary antioxidant activities of nine edible mushrooms species
}

\author{
${ }^{1}$ Muhammad Ezzudin, R., ${ }^{1 *}$ Rabeta, M.S., ${ }^{2}$ Shaida Fariza, S., ${ }^{2}$ Leong Ooi, K. and \\ ${ }^{2}$ Nurul Shafiqah, $\mathrm{H}$. \\ ${ }^{1}$ Food Technology Division, School of Industrial Technology, Universiti Sains Malaysia, 11800 Minden, \\ Penang, Malaysia. \\ ${ }^{2}$ School of Biological Sciences, Universiti Sains Malaysia, 11800 Minden, Penang, Malaysia
}

\begin{abstract}
Article history:
Received: 31 March 2018

Received in revised form: 12

June 2018

Accepted: 20 June 2018

Available Online: 22 June

2018
\end{abstract}

\section{Keywords:}

Antioxidant activity,

Total phenolic content,

Mushrooms

DOI:

https://doi.org/10.26656/fr.2017.3(1).077

\begin{abstract}
In this study, nine different edible mushrooms, namely bunapi, maitake, bunashimeji, abalone, oyster, button, white, enoki and kukur evaluated for antioxidant activities and total phenolic content (TPC). Specifically, three different antioxidant assays which were 1,1-diphenyl-2-picrylhydrazyl (DPPH) free radical scavenging, ferric reducing antioxidant power (FRAP) and metal chelating (MC) used. From the evaluation, button mushrooms were identified to scavenge free radicals and reduce lipid peroxidation with the lowest $\mathrm{EC}_{50}$ of $23.40 \pm 2.56 \mathrm{mg} / \mathrm{mL}$ in methanol extract. Besides, the highest ferric reducing antioxidant power and metal chelating activities were exhibited by button mushroom in water extract at $25.47 \pm 2.52 \mathrm{mg} / \mathrm{mL}$ and enoki in methanol extract at $1.00 \pm 0.16 \mathrm{mg} / \mathrm{mL}$, respectively. On the other hand, the highest contents of total phenolics were recorded in a water extract of kukur with $211.35 \pm 11.89 \mu \mathrm{g}$ GAE/g extract and methanol extract of maitake with $400.28 \pm 11.35 \mu \mathrm{g} \mathrm{GAE} / \mathrm{g}$ extract. However, there was no correlation between the antioxidant activity and total phenolic content because the activity of DPPH, FRAP and metal chelating revealed different lowest $\mathrm{EC}_{50}$ value when associated with different species of mushrooms. Hence, this study showed the antioxidant values of nine edible mushrooms species, which can serve as a useful database for the selection of mushrooms in food, pharmaceuticals and nutraceuticals industries.
\end{abstract}

\section{Introduction}

In general terms, primary antioxidant or chain breaking antioxidant is a compound that reacts with radicals to convert them into more stable products. For instance, alkyl peroxy radical, $\mathrm{ROO} \bullet$ is a significant lipid radical at normal oxygen pressures that functions as an oxidizing agent which may be directly converted into a hydroperoxide by a hydrogen donor (Gordon, 1990). Conversely, secondary antioxidants are compounds that inhibit the autoxidation of lipids and interrupt the autoxidation chain by converting free radicals into more stable species (Lobo et al., 2010). Among the mechanisms available which could inhibit the rate of autoxidation are metal ion binding, oxygen scavenging, UV radiation absorption or singlet oxygen deactivation and decomposition of hydroperoxides into non-radical species (Lü et al., 2010). In fact, metal ions and reducing agents such as ascorbic acid have identified as active sequestering agents in revealing secondary antioxidant in the presence of tocopherols or other phenolic compounds (Gordon, 1990).
Mainly, a mushroom is a macrofungus with a distinctive fruiting body which can be either epigeous (above ground) or hypogeous (underground) and visible to our naked eyes (Miles and Chang, 2004). Mushrooms can be classified into six different groups according to their morphological characteristics (Fitts, 1961). To this classification, the groups are basidiomycetes (spore or reproductive bodies are naked), ascomycetes (spores enclosed in sacs or asci), physcomycetes, myxomycetes (slime moulds), saccharomycetes (yeast fungi) and schizomycetes. Fungi can live in three different conditions which are saprophytic, parasitic and symbiotic. In this context, saprophytic mushrooms will use their enzymes to break down the organic matter inside mushrooms. For instance, one of the examples of saprophytic fungi is the shaggy ink cup (Coprinus comatus). Secondly, parasitic mushrooms are mushrooms that grow on trees and absorb nutrients from the trees. One species which falls this category is The Honey Fungus (Armillaria mellea). Thirdly, symbiotic fungi mushrooms are essential components of stream ecosystems and critical intermediaries in the transfer of carbon, nutrients, and energy to higher trophic levels 
(Gulis and Bärlocher, 2017).

Furthermore, the antioxidant activity of different edible mushroom extracts plays a significant role in absorbing and neutralizing free radicals in a deleterious molecule, decomposing the peroxide and quenching singlet and triplet oxygen (Osawa, 1994). In fact, based on a proximate analysis conducted by Wang et al. (2014), edible mushrooms were discovered to be rich in carbohydrate, protein and essential minerals (potassium, calcium, and magnesium). Besides, ascorbic acid, tocopherols, phenolics, flavonoids, and carotenoids are among the group of compounds present in mushrooms with antioxidant activity (Ferreira et al., 2009). Moreover, mushrooms have acknowledged as a nutritious and healthy food due to the bioactive compounds namely phenolic which have the ability in scavenging free radical, reducing ferric to ferrous ion and chelating metal ion (Decker, 1997). Additionally, edible mushrooms could be used directly to increase our dietary antioxidant intake (Kozarski et al., 2015). Enokitake (Flammulina velutipes), shiitake (Lentinula edodes) and split gill mushrooms (Schizopyllum commune) were locally cultivated in Malaysia while button mushrooms (Agaricus bisporus), Nameko (Pholiota nameko) and Hypsizygus sp. were imported from other countries (Lee et al., 2009).

To date, studies to determine the antioxidant activities in mushrooms remain insufficient. Studies on the antioxidant activity of mushrooms in Malaysia are mostly focused on primary antioxidant (Arbaayah and Kalsom, 2013) and less on secondary antioxidant activity. Moreover, samples of mushrooms for research were limited and only the well-known species such as Pleurotus spp. and shiitake (Lentinula edodes) were given preference. Therefore, this comparative study was performed to determine the primary and secondary antioxidant activities of nine edible mushrooms species commonly consumed in Malaysia and identify mushrooms with the highest antioxidant activity.

\section{Materials and methods}

\subsection{Samples preparation}

Nine species of edible mushrooms were bought from three different supermarkets around Penang Island which are Tesco Sungai Dua, Queensbay Mall and Giant Hypermarket in Bukit Gedung. Blanched samples were blended, and the juices were squeezed out, prior to analysis.

\subsection{Water extraction}

The extraction method was prepared according to the procedure used by Ooi et al. (2011) with slightly modification. The sample was ground using a Smart Lady blender juice and was then put on the muslin cloth. The juice was squeezed out and was put in $250 \mathrm{~mL}$ beaker. The juice was then put into a $50 \mathrm{~mL}$ centrifuge tubes and were kept in the $-20^{\circ} \mathrm{C}$ laboratory freezer prior to analysis. The residue of samples was extracted with methanol. All extractions were performed in triplicate.

\subsection{Methanol extraction}

The residue was weighed using electronic beam balance (BEL Engineering) and put it into $250 \mathrm{~mL}$ beaker. Methanol $(100 \%)$ was added to the beaker 5 times higher than the weight of the filtrate. The ratio of the filtrate to the $100 \%$ methanol added was 1:5. Then, the mixture was boiled for about 20 minutes. After that, the extract was filtered using muslin cloth in $250 \mathrm{~mL}$ beaker. Finally, the methanol extract was added to a 50 $\mathrm{mL}$ centrifuge tube prior to analysis (Ooi et al., 2011). All extractions were carried out in triplicate.

\subsection{Determination of DPPH assay}

About $50 \mu \mathrm{L}$ of the prepared extracts were loaded to each well of the 96-microwell plate. A $150 \mu \mathrm{L}$ of 0.3 $\mathrm{mM}$ 1,1-diphenyl-2-picrylhydrazyl was pipetted into each well that contained the extracts using multi-channel pipette in the dark room. The total amount of solution in each well was $200 \mu \mathrm{L}$. The quercetin was used as a positive control while dimethyl sulfoxide (DMSO) as a negative control. Then, 96-microwell plate was wrapped in aluminium foil before incubated for 30 minutes at $37^{\circ}$ C. The absorbance reading was taken after 30 minutes using Multiskan Spectrum (Thermo Scientific) at wavelength $515 \mathrm{~nm}$ (Brand-Williams et al., 1995). The results obtained was compared with the positive control, quercetin. The purple colour of the DPPH will turn to yellow when the sample had an antioxidant activity. The ability of the extracts to scavenge at $50 \%$ of the DPPH, $\mathrm{EC}_{50}$ was determined from the graph plotted in GraphPad Prism software. All experiments were carried out in triplicate.

\subsection{Determination of FRAP assay}

A $50 \mu \mathrm{L}$ of the extracts was pipetted into the plates. Then, $150 \mu \mathrm{L}$ of FRAP reagent was added directly to each well Trolox was used as a positive control while DMSO as a negative control of the experiment. Then, 96 -microwell plate was incubated at $37^{\circ} \mathrm{C}$ for 30 minutes before measuring the absorbance. After $30 \mathrm{mins}$ incubated in the incubator, the absorbance of the extracts was measured using Multiskan Spectrum (Thermo Scientific) at a wavelength of $593 \mathrm{~nm}$ (Benzie and Strain, 1996). The absorbance of the extracts was compared with the positive control, Trolox. The colour of the FRAP turns to deep blue when there was an antioxidant 
activity. The $\mathrm{EC}_{50}$ was determined from the graph that was plotted in GraphPad Prism software. All experiments were performed in triplicate.

\subsection{Determination of metal chelating assay}

Approximately $50 \mu \mathrm{L}$ of each extract was incubated with $5 \mu \mathrm{l}$ ferrous chlorides and $130 \mu \mathrm{L}$ of deionized water for $10 \mathrm{mins}$ at $37^{\circ} \mathrm{C}$. The mixture was added with $15 \mu \mathrm{L}$ of ferrozine which initiated the reactions. The mixture then was incubated for $10 \mathrm{mins}$ at $37^{\circ} \mathrm{C}$. After 10 mins of incubation, the absorbance of the extracts was quickly read by Multiskan Spectrum (Thermo Scientific) at wavelength $562 \mathrm{~nm}$ (Dinis et al., 1994). The absorbance of the extracts was compared to the Ethylenediaminetetraacetic acid (EDTA) as a positive control. DMSO was used as the negative control and ferrous chloride was used as background in this test. The colour of the metal chelating assay will turn from bright purple to pale purple when there was an antioxidant activity. The ability of the ferrous ion to be $50 \%$ chelated by the extracts was determined as $\mathrm{EC}_{50}$ from the graph plotted in GraphPad Prism software. All experiments were carried out at least three replicates.

\subsection{Determination of total phenolic content}

Approximately $50 \mu \mathrm{L}$ of prepared extracts was loaded to the 96-microwell plate. A $25 \mu \mathrm{L}$ of the FolinCiocalteu (FC) solution was added to the extracts (Singleton et al., 1999). The mixture was incubated for 5 mins at room temperature $\left(28^{\circ} \mathrm{C}\right)$. After 5 minutes of incubation, $25 \mu \mathrm{L}$ of $2 \%$ sodium carbonate $\left(\mathrm{NaCO}_{3}\right)$ solution was added to the mixture followed by $100 \mu \mathrm{L}$ of distilled water to a final volume of $200 \mu \mathrm{L}$ per well. Then, the mixture was incubated for about $30 \mathrm{mins}$ at room temperature $\left(28^{\circ} \mathrm{C}\right)$ before the reading was taken using Multiscan Spectrum (Thermo Scientific) at wavelength of $750 \mathrm{~nm}$. The absorbance obtained was compared to the positive control, gallic acid. All experiments were performed in triplicate. The results expressed as microgram gallic acid equivalent per gram extracts ( $\mu \mathrm{g}$ GAE /g extract).

\subsection{Statistical analysis}

The results expressed as the mean standard deviation (SD). Statistical analysis of data was carried out using SPSS version 20.0. Significant differences between means calculated by using Duncan's multiple range tests at a level of $p<0.05$.

\section{Results and discussion}

\subsection{DPPH scavenging activity of the samples}

As shown in Table 1, for the DPPH assay, white mushrooms $(97.05 \pm 19.21 \%)$ and bunashimeji $(92.14 \pm 2.86 \%)$ possessed the highest percentage of scavenging activity in aqueous extract followed by bunapi, oyster, button, kukur, abalone, and enoki. The lowest scavenging activity was recorded by maitake with the percentage value at $13.39 \pm 1.96 \%$.

The methanolic button mushroom extract exhibited the highest scavenging free radical activity with the value of $77.62 \pm 8.11 \%$. Next, enoki was ranked second highest at $70.70 \pm 3.58 \%$. In this study, bunapi, bunashimeji, oyster, maitake and abalone mushrooms were identified to possess moderate percentage values ranging from $37.39 \pm 3.32 \%$ to $24.67 \pm 1.53 \%$. Also, white mushroom and kukur had the least effective scavenging activity with the lowest percentage of $17.81 \pm 1.15 \%$ and $15.09 \pm 1.34 \%$, respectively.

In contrast, button mushroom was exhibited the lowest EC50 value of $23.40 \pm 2.56 \mathrm{mg} / \mathrm{mL}$ compared to other mushrooms both in aqueous and methanolic extracts. However, the comparison of methanol and water extracts did not show any significant difference $(p>0.05)$. The sequence of antioxidant activity in DPPH test of aqueous and methanolic extracts was as follows:

Button (methanol) $>$ Enoki (methanol) $>$ Bunapi (water) $>$ Bunashimeji (water) $>$ White (water)

In this study, the result agrees with a study done by Fu et al. (2002), where the best result of scavenging

Table 1. The $\mathrm{EC}_{50}$ values of the DPPH scavenging activity of water and methanol extracts.

\begin{tabular}{ccccc}
\hline & \multicolumn{2}{c}{ Water Extract } & \multicolumn{2}{c}{ Methanol Extract } \\
\cline { 2 - 5 } Samples & $\begin{array}{c}\text { Percentage of } \\
\text { scavenging activity }(\%)\end{array}$ & $\begin{array}{c}\mathrm{EC}_{50} \text { of DPPH Scavenging } \\
\text { activity }(\mathrm{mg} / \mathrm{mL})\end{array}$ & $\begin{array}{c}\text { Percentage of } \\
\text { scavenging activity }(\%)\end{array}$ & $\begin{array}{c}\text { EC } \\
50 \\
\text { of DPPH Scavenging } \\
\text { activity }(\mathrm{mg} / \mathrm{mL})\end{array}$ \\
\hline Bunapi & $69.18 \pm 3.73$ & $68.31 \pm 3.55$ & $37.39 \pm 3.32$ & $*$ ND \\
Maitake & $13.39 \pm 1.96$ & $* \mathrm{ND}$ & $25.16 \pm 2.33$ & $* \mathrm{ND}$ \\
Bunashimeji & $92.14 \pm 2.86$ & $133.10 \pm 34.43$ & $34.97 \pm 0.51$ & $* \mathrm{ND}$ \\
Abalone & $37.19 \pm 3.86$ & $* \mathrm{ND}$ & $24.67 \pm 1.53$ & $* \mathrm{ND}$ \\
Oyster & $48.63 \pm 2.34$ & $* \mathrm{ND}$ & $31.50 \pm 1.76$ & $* \mathrm{ND}$ \\
Button & $38.59 \pm 22.05$ & $* \mathrm{ND}$ & $77.62 \pm 8.11$ & $23.40 \pm 2.56$ \\
White & $97.05 \pm 19.21$ & $165.97 \pm 15.25$ & $70.70 \pm 3.58$ & $* \mathrm{ND}$ \\
Enoki & $34.82 \pm 3.73$ & $* \mathrm{ND}$ & $15.09 \pm 1.34$ & $35.86 \pm 1.58$ \\
Kukur & $38.01 \pm 0.43$ & $* \mathrm{ND}$ & $78.15 \pm 0.70$ & $* \mathrm{ND}$ \\
Quercetin & $78.15 \pm 0.70$ & - & & - \\
\hline
\end{tabular}

Key: $*$ ND $=$ Not Determined 
Table 2. The $\mathrm{EC}_{50}$ values of the ferric reducing activity of water and methanol extracts.

\begin{tabular}{ccccc}
\hline \multirow{2}{*}{ Samples } & \multicolumn{2}{c}{ Water Extract } & \multicolumn{2}{c}{ Methanol Extract } \\
\cline { 2 - 5 } & $\begin{array}{c}\text { Percentage of } \\
\text { reducing activity }(\%)\end{array}$ & $\begin{array}{c}\text { EC }_{50} \text { of FRAP reducing } \\
\text { activity }(\mathrm{mg} / \mathrm{mL})\end{array}$ & $\begin{array}{c}\text { Percentage of } \\
\text { reducing activity }(\%)\end{array}$ & $\begin{array}{c}\text { EC }_{50} \text { of FRAP reducing } \\
\text { activity }(\mathrm{mg} / \mathrm{mL})\end{array}$ \\
\hline Bunapi & *ND & $15.95 \pm 1.06$ & *ND & $16.54 \pm 1.24$ \\
Maitake & *ND & $39.46 \pm 0.34$ & *ND & $14.63 \pm 2.52$ \\
Bunashimeji & *ND & $14.99 \pm 0.89$ & *ND & $16.39 \pm 0.98$ \\
Abalone & *ND & $16.35 \pm 0.10$ & *ND & $11.19 \pm 1.36$ \\
Oyster & *ND & $24.42 \pm 6.63$ & *ND & $15.16 \pm 1.50$ \\
Button & $25.47 \pm 2.52$ & $84.60 \pm 0.00$ & *ND & $43.91 \pm 0.49$ \\
White & *ND & $17.06 \pm 0.08$ & *ND & $20.35 \pm 0.25$ \\
Enoki & *ND & $12.86 \pm 0.11$ & *ND & $24.43 \pm 1.24$ \\
Kukur & *ND & $48.69 \pm 2.52$ & $73.25 \pm 0.34$ & $12.57 \pm 1.24$ \\
Trolox & $73.25 \pm 0.34$ & - & & - \\
\hline
\end{tabular}

Key: $*$ ND $=$ Not Determined

activity observed in button mushrooms, Agaricus bisporous when methanol extract used. This result might be due to the significant amount of phenolic amino acids such as tyrosine, L-glutaminyl-4-hydroxybenzene and ascorbic acid which promoted the scavenging activity (Choi and Sapers, 1994).

\subsection{FRAP assay of the samples}

In Table 2, button possessed the highest reducing activity with the value of $84.60 \%$ at the highest concentration in water extract then followed by kukur and maitake at $48.69 \pm 2.52 \%$ and $39.46 \pm 0.34 \%$, respectively. Next, oyster produced a percentage of $24.42 \pm 6.63 \%$ when tested at the highest concentration. On the other hand, the average percentage of reducing activity was white, abalone, bunapi, and bunashimeji at $17.06 \pm 0.08 \%, \quad 16.35 \pm 0.10 \%, \quad 15.95 \pm 1.06 \% \quad$ and $14.99 \pm 0.89 \%$, respectively. In fact, the lowest percentage of ferric reducing activity was exhibited by enoki only at $12.86 \pm 0.11 \%$.

Button mushroom also exhibited the highest ferric reducing activity when examined with methanolic extract which resulted in the value of $43.91 \pm 0.49 \%$. The list then followed by enoki and white mushrooms with the percentage of $24.43 \pm 1.24 \%$ and $20.35 \pm 0.251 \%$, respectively. Next, bunapi, bunashimeji, oyster and maitake possessed the moderate percentage values of $16.54 \pm 1.24 \%, \quad 16.39 \pm 0.98 \%, \quad 15.16 \pm 1.50 \% \quad$ and $14.63 \pm 2.52 \%$, respectively. For the values obtained, kukur and abalone classified as mushrooms with the least ferric reducing activity with the lowest percentage at $12.57 \pm 1.24 \%$ and $11.19 \pm 1.36 \%$, respectively.

In this assay, the highest antioxidant potential with the lowest $\mathrm{EC}_{50}$ value also exhibited by button mushroom. However, it should note that it was only in the water extract that activity occurred with the $\mathrm{EC}_{50}$ value of $25.47 \pm 2.52 \%$. Conversely, the $\mathrm{EC}_{50}$ for the other mushrooms extracts were unable to be determined. For instance, at $(p<0.05)$, in relation to this study, there was a significant difference between water and methanol extracts $\mathrm{EC}_{50}$. According to Gan et al. (2013), the water extract of button mushroom is an effective source of activity reduction compared to ethanol. In this context, this might be due to the presence of extraction solvent and test system used (Fu et al., 2010).

\subsection{Metal chelating assay of the samples}

As demonstrated in Table 3, white mushrooms exhibited the highest percentage of metal chelating activity with the value of $99.95 \pm 0.50 \%$ when tested at the highest concentration in water extract. The kukur mushroom followed this with a reading of $99.27 \pm 2.79 \%$

Table 3. The $\mathrm{EC}_{50}$ values of the metal chelating activity of water and methanol extracts.

\begin{tabular}{ccccc}
\hline \multirow{2}{*}{ Samples } & \multicolumn{2}{c}{ Water Extract } & \multicolumn{2}{c}{ Methanol Extract } \\
\cline { 2 - 5 } & $\begin{array}{c}\text { Percentage of } \\
\text { chelating activity }(\%)\end{array}$ & $\begin{array}{c}\mathrm{EC}_{50} \text { of metal chelating } \\
\text { activity }(\mathrm{mg} / \mathrm{mL})\end{array}$ & $\begin{array}{c}\text { Percentage of } \\
\text { chelating activity }(\%)\end{array}$ & $\begin{array}{c}\mathrm{EC}_{50} \text { of metal chelating } \\
\text { activity }(\mathrm{mg} / \mathrm{mL})\end{array}$ \\
\hline Bunapi & $95.00 \pm 4.84$ & $3.34 \pm 0.22$ & $90.98 \pm 4.82$ & $1.06 \pm 0.13$ \\
Maitake & $82.33 \pm 6.65$ & $7.54 \pm 0.31$ & $98.45 \pm 0.57$ & $2.89 \pm 0.06$ \\
Bunashimeji & $88.23 \pm 6.52$ & $3.82 \pm 0.15$ & $99.45 \pm 0.27$ & $1.15 \pm 0.12$ \\
Abalone & $94.48 \pm 0.18$ & $50.30 \pm 0.74$ & $99.60 \pm 4.87$ & $1.95 \pm 0.29$ \\
Oyster & $91.12 \pm 2.30$ & $6.38 \pm 0.59$ & $92.68 \pm 0.25$ & $5.11 \pm 0.17$ \\
Button & $89.51 \pm 0.61$ & $30.34 \pm 0.57$ & $94.42 \pm 9.03$ & $1.26 \pm 0.06$ \\
White & $99.95 \pm 0.5$ & $2.42 \pm 0.16$ & $99.23 \pm 10.04$ & $1.51 \pm 0.08$ \\
Enoki & $98.38 \pm 0.20$ & $30.62 \pm 0.75$ & $99.49 \pm 0.79$ & $1.00 \pm 0.16$ \\
Kukur & $99.27 \pm 2.79$ & $25.54 \pm 2.04$ & $35.64 \pm 0.18$ & $*$ ND \\
EDTA & $95.86 \pm 0.18$ & - & $95.86 \pm 0.18$ & - \\
\hline
\end{tabular}

Key: $* \mathrm{ND}=$ Not Determined 
at the highest concentration. Meanwhile, enoki, bunapi, abalone, oyster, button and bunashimeji mushrooms produced a relatively average percentage of metal chelating activity. Concerning this finding, maitake was identified to have the lowest metal chelating activity with the percentage value of $82.33 \pm 6.65 \%$.

On the other hand, in methanol extract abalone mushroom possessed the highest metal chelating activity with the value of $99.60 \pm 4.87 \%$ at the highest concentration. Then, the order continued with enoki and bunashimeji at $99.49 \pm 0.79 \%$ and $99.45 \pm 0.27 \%$, respectively. Lastly, the white mushrooms recorded a percentage of $99.23 \pm 10.04 \%$ at its highest concentration. Moreover, it also discovered that mushrooms with the average percentage of metal chelating activity were enoki, maitake, button, oyster, and bunapi ranging from $99.23 \pm 10.04 \%$ to $90.98 \pm 4.83 \%$, respectively. In connection with this study, the lowest percentage of metal chelating activity was exhibited by kukur only at $35.64 \pm 0.18 \%$.

Additionally, enoki mushroom (Flammulina velutipes) of methanol extract produced the lowest $\mathrm{EC}_{50}$ value of $1.00 \pm 0.16 \mathrm{mg} / \mathrm{mL}$. In this respect, this reading might potentially influence by the presence of solid active compounds presence such as phenol and flavonoid that exhibit favorable chelating of $\mathrm{Fe}^{2+}$ activity (Ebrahimzadeh et al., 2008). Particularly, bunapi, bunashimeji and white mushrooms of methanol extract showed lower $\mathrm{EC}_{50}$ value with $1.06 \pm 0.13 \mathrm{mg} / \mathrm{mL}$, $1.15 \pm 0.12 \mathrm{mg} / \mathrm{mL}$ and $1.51 \pm 0.08 \mathrm{mg} / \mathrm{mL}$, respectively compared to water extract at $3.34 \pm 0.22 \mathrm{mg} / \mathrm{mL}$, $3.82 \pm 0.15 \mathrm{mg} / \mathrm{mL}$ and $3.66 \pm 0.12 \mathrm{mg} / \mathrm{mL}$, respectively. Based on the results recorded, there were no significant differences found between water and methanol extracts of $\mathrm{EC}_{50}$ at $(p>0.05)$.

\subsection{Total phenolic content}

Table 4 showed that among the water extracts, the highest total phenolic content exhibited by kukur and this was followed by maitake which produced readings of $211.35 \pm 11.89 \mu \mathrm{g}$ GAE/g extract and $129.44 \pm 1.06 \mu \mathrm{g}$ GAE/g extract, respectively. Total phenolics are the major naturally occurring antioxidant components found in Kukur followed by Maitake in water extract. About this study, the lowest total phenolics content was enoki mushrooms with $30.97 \pm 1.78 \mu \mathrm{g} \mathrm{GAE} / \mathrm{g}$ extract while the other extracts showed moderate of total phenolic contents. Moreover, among the methanol extracts, the highest total phenolic content was exhibited by the maitake mushrooms at $400.28 \pm 11.35 \mu \mathrm{g} \mathrm{GAE} / \mathrm{g}$ extract, and the lowest was kukur at $3.58 \pm 0.70 \mu \mathrm{g}$ GAE/g extract. On the other hand, the remaining showed moderate of total phenolic content.
Table 4. Total phenolic content of water and methanol extracts.

\begin{tabular}{ccc}
\hline \multirow{2}{*}{ Samples } & \multicolumn{2}{c}{ Total phenolic content $(\mu \mathrm{g}$ GAE/g extract $)$} \\
\cline { 2 - 3 } & Water Extract & Methanol Extract \\
\hline Bunapi & $84.97 \pm 0.61$ & $36.34 \pm 3.64$ \\
Maitake & $129.44 \pm 1.06$ & $400.28 \pm 11.35$ \\
Bunashimeji & $69.52 \pm 0.53$ & $74.69 \pm 0.66$ \\
Abalone & $45.77 \pm 0.22$ & $15.16 \pm 1.02$ \\
Oyster & $38.56 \pm 2.90$ & $15.42 \pm 1.54$ \\
Button & $33.13 \pm 0.49$ & $56.26 \pm 1.50$ \\
White & $74.69 \pm 0.66$ & $16.18 \pm 0.73$ \\
Enoki & $30.97 \pm 1.78$ & $35.49 \pm 0.45$ \\
Kukur & $211.35 \pm 11.89$ & $3.58 \pm 0.70$ \\
\hline
\end{tabular}

Key: *ND = Not Determined

In this study, the highest total phenolic content was displayed by methanol extract of Maitake mushrooms (Grifola frondosa) at $400.28 \pm 11.35 \mu \mathrm{g}$ GAE/g extract. Besides, most mushrooms of the water extract also exhibited higher total phenolic contents compared to methanol extracts such as kukur and bunapi at $211.35 \pm 11.89 \mu \mathrm{g}$ GAE/g extract and $84.97 \pm 0.61 \mu \mathrm{g}$ $\mathrm{GAE} / \mathrm{g}$ extract, respectively. In this respect, it deduced that there is a significant difference between water and methanol extracts $\mathrm{EC}_{50}$ at $(p<0.05)$.

Contrariwise, a study conducted by Mau et al. (2002) had shown that methanolic extract of maitake mushrooms contains moderate content of total phenolics compared to the others three mushrooms which are Dictophora indusiata, Hericium erinaceus, and Tricholoma giganteum. However, these mushrooms not used in this study. In other words, the differences in total phenolic content suggest that they might have contributed by the sample processing method and extraction method or the cultivar studied. A group of researchers also highlighted that the major phenolic compounds found in mushrooms are phenolic acids (Ferreira et al., 2009). The nine edible mushrooms used in this study could be categorized into three groups based on their phenolics content as low, moderate, and high phenolic species (Puttaraju et al., 2006). Thus, it can be concluded that the total phenolic content of the methanol extract of maitake was the highest compared to the other mushrooms in water extract.

\section{Conclusion}

In conclusion, it can be deduced from the results that there is no correlation between the antioxidant activity and total phenolic content because the activity of DPPH, FRAP and metal chelating showed that the different mushrooms exhibited the lowest $\mathrm{EC}_{50}$ value with phenolics content. Therefore, the $50 \%(\mathrm{v} / \mathrm{v})$ water extract of white mushroom can be used as a potential natural antioxidative source in food industries. Based on the 
results of this study, a few suggestions were established to improve this research in the future. For instance, one of the recommendations includes increasing the number of mushrooms samples by including various species such as Shiitake (Lentinula edodes), Jeli Hitam (Auricularia sp.) and Ganoderma (Ganoderma sp.) to increase the validity of the results regarding the antioxidant activity. Hence, this study revealed the antioxidant values of nine edible mushrooms species, which can serve as a useful database for the selection of mushrooms in food, pharmaceuticals and nutraceuticals industries.

\section{Conflict of interest}

The authors declared no conflict of interest.

\section{Acknowledgment}

School of Biological Sciences, Universiti Sains Malaysia 11800 Minden, Penang, Malaysia contributed to the funding of this research.

\section{References}

Arbaayah, H. and Kalsom, Y. (2013). Antioxidant properties in the oyster mushrooms (Pleurotus spp.) and split gill mushroom (Schizophyllum commune) ethanolic extracts. Mycosphere, 4(4), 661-673.

Benzie, I.F. and Strain, J.J. (1996). The ferric reducing ability of plasma (FRAP) as a measure of "antioxidant power": the FRAP assay. Analytical Biochemistry, 239(1), 70-76. https://doi.org/10.1006/ abio.1996.0292

Brand-Williams, W., Cuvelier, M.-E. and Berset, C. (1995). Use of a free radical method to evaluate antioxidant activity. LWT-Food Science and Technology, 28(1), 25-30. https://doi.org/10.1016/ S0023-6438(95)80008-5

Choi, S.W. and Sapers, G.M. (1994). Effects of washing on polyphenols and polyphenol oxidase in commercial mushroom (Agaricus bisporus). Journal of Agriculture and Food Chemistry, 42(10), 22862290. https://doi.org/10.1021/jf00046a038

Decker, A. (1997). Phenolics: prooxidants or antioxidants? Nutrition Review, 55(11), 396-398.

Dinis, T.C., Madeira, V.M. and Almeida, L.M. (1994). Action of phenolic derivatives (acetaminophen, salicylate, and 5-aminosalicylate) as inhibitors of membrane lipid peroxidation and as peroxyl radical scavengers. Archives of Biochemistry and Biophysics, 315(1), 161-169. https://doi.org/10.1006/ abbi.1994.1485

Ebrahimzadeh, M.A., Pourmorad, F. and Bekhradnia, A.R. (2008). Iron chelating activity, phenol and flavonoid content of some medicinal plants from Iran. African Journal of Biotechnology, 7(18), 31883192

Ferreira, I.C., Barros, L. and Abreu, R. (2009). Antioxidants in wild mushrooms. Current Medicinal Chemistry, 16(12), 1543-1560. https:// doi.org/10.2174/092986709787909587

Fu, H.Y., Shieh, D.E. and Ho, C.T. (2002). Antioxidant and free radical scavenging activities of edible mushrooms. Journal of Food Lipid, 9(1), 35-43. https://doi.org/10.1111/j.1745-4522.2002.tb00206.x

Fitts, D.D. (1961). The mushrooms: edible and otherwise its habitat and its time of growth. $12^{\text {th }}$ ed. New York: Hafner Publishing Company.

Gan, C., Nurul Amira, B. and Asmah, R. (2013). Antioxidant analysis of different types of edible mushrooms (Agaricus bisporous and Agaricus brasiliensis). International Food Research Journal, 20(3), 1095-1102.

Gordon, M.H. (1990). The mechanism of antioxidant action in Vitro. In Hudson, B.J.F. (Ed.) Food Antioxidants. Elsevier Applied Food Science Series, p. 1-18. Dordrecht: Springer. https:// doi.org/10.1007/978-94-009-0753-9_1

Gulis, V. and Bärlocher, F. (2017). Fungi: Biomass, Production and Community Structure. In Hauer, R.F. and Lamberti, G.A. (Eds.) Methods in Stream Ecology. Vol. 1, 3rd ed., p. 177-192. USA: Academic Press. https://doi.org/10.1016/B978-0-12416558-8.00010-X

Kozarski, M., Klaus, A., Jakovljevic, D., Todorovic, N., Vunduk, J., Petrović, P., Niksic, M., Vrvic, M.M. and van Griensven, L. (2015). Antioxidants of Edible Mushrooms. Molecules, 20(10), 1948919525. https://doi.org/10.3390/molecules201019489

Lee, S., Chang, Y. and Noraswati, M. (2009). Utilization of macrofungi by some indigenous communities for food and medicine in Peninsular Malaysia. Forest Ecology and Management, 257(10), 2062-2065. https://doi.org/10.1016/j.foreco.2008.09.044

Lobo, V., Patil, A., Phatak, A. and Chandra, N. (2010). Free radicals, antioxidants and functional foods : Impact on human health. Pharmacognosy Review, 4 (8), 118-126. https://doi.org/10.4103/09737847.70902

Lü, J-M., Lin, P.H., Yao, Q. and Chen, C. (2010). Chemical and molecular mechanisms of antioxidants: experimental approaches and model systems. Journal of Cellular and Molecular Medicine, 14(4), 840-860. https://doi.org/10.1111/ j.1582-4934.2009.00897.x

Mau, J. L., Lin, H.C. and Song, S.F. (2002). Antioxidant 
properties of several specialty mushrooms. Food Research International, 35(6), 519-526. https:// doi.org/10.1016/S0963-9969(01)00150-8

Miles, P.G. and Chang, S.T. (2004). Mushrooms: cultivation, nutritional value, medicinal effect, and environmental impact. USA: CRC Press.

Ooi, K.L., Muhammad, T.S.T., Tan, M.L. and Sulaiman, S.F. (2011). Cytotoxic, apoptotic and anti- $\alpha-$ glucosidase activities of 3, 4-di-O-caffeoylquinic acid, an antioxidant isolated from the polyphenolicrich extract of Elephantopus mollis Kunth. Journal of Ethnopharmacology, 135(3), 685-695. https:// doi.org/10.1016/j.jep.2011.04.001

Osawa, T. (1994). Novel natural antioxidant for utilization in food and biological systems. Postharvest Biochemistry of Plant Food Materials in Tropics, p. 241-251. Tokyo: Japan Scientific Press

Puttaraju, N.G., Venkateshaiah, S.U., Dharmesh, S.M., Nanjaraj Urs, S.M. and Somasundaram, R. (2006). Antioxidant Activity of Indigenous Edible Mushrooms. Journal of Agricultural and Food Chemistry, 54(26), 9764-9772. https:// doi.org/10.1021/jf0615707

Singleton, V.L., Orthofer, R. and Lamuela-Raventós, R. M. (1999). Analysis of total phenols and other oxidation substrates and antioxidants by means of Folin-Ciocalteu reagent. Methods in Enzymology, 299, 152-178. https://doi.org/10.1016/S0076-6879 (99)99017-1

Wang, X.M., Zhang, J., Wu, L.H., Zhao, Y.L., Li, T., Li, J.Q., Wang, Y.Z. and Liu, H.-G. (2014). A minireview of chemical composition and nutritional value of edible wild-grown mushroom from China. Food Chemistry, 151, 279-285. https:// doi.org/10.1016/j.foodchem.2013.11.062 